\title{
Formação em Epidemiologia para Profissionais de Saúde na Atual Conjuntura Sanitária
}

José Eluf Neto*

A importância e desenvolvimento recente da Epidemiologia em nível nacional e internacional tornam vital pensar a formação atual de recursos humanos na área, assim como os modos de estimular e aprimorar esta formação. Não se pretende aqui fazer uma análise abrangente, mas levantar algumas dúvidas e questões a partir da experiência como aluno de Pós-Graduação e posteriormente docente do Departamento de Medicina Preventiva da Faculdade de Medicina - USP, e um pouco daquela vivida no exterior como Pós-Graduando. As questões serão restritas à formação em Epidemiologia nos cursos de Residência e Mestrado/Doutorado. Como subsídio será utilizado parte do material e algumas discussões sobre o tema da "II Reunião Nacional de Avaliação e Perspectivas (1984-1994) - Os Rumos da Epidemiologia Brasileira", realizada em 1994 em Olinda.

Inicialmente deve-se perguntar sobre o papel que a Epidemiologia desempenhou para a configuração da atual conjuntura sanitária. Não obstante a posição praticamente consensual de que critérios epidemiológicos (não de modo exclusivo) deveriam nortear a política e a definição de prioridades em saúde, é forçoso reconhecer que a atual conjuntura sanitária pouco dependeu de princípios e critérios epidemiológicos. Embora de extrema relevância, não se buscará fazer aqui uma análise das razões para isto ter ocorrido.

As colocações a seguir dizem respeito principalmente à formação de médicos. Apesar de há vários anos o Departamento de Medicina Preventiva da FMUSP oferecer curso de Aprimoramento para outros profissionais, aparentemente nenhum deles se encaminhou para a área de Epidemiologia. Este fato

\footnotetext{
* Professor Doutor do Departamento de Medicina Preventiva da FM da USP.
} 
permite lançar uma questão: por que existem poucos epidemiologistas nãomédicos em nosso meio? Em outros países, alguns dos mais renomados epidemiologistas não são médicos (muitos são estatísticos).

Para se pensar a área de Epidemiologia na Residência, deve-se tomar como ponto de partida a redução na oferta e preenchimento de vagas nos Programas de Residência em Medicina Preventiva/Saúde Coletiva. Segundo o documento da Reunião de Olinda, entre 1984 e 1991 a oferta de vagas nessa área foi reduzida em aproximadamente $10 \%$; mais preocupante foi a queda no preenchimento de vagas - cerca de $42 \%$. O Estado de São Paulo seria responsável por cerca de $50 \%$ das vagas do país. Diversos fatores foram apontados para explicar esta redução na demanda: o atual modelo assistencial que torna praticamente desnecessária a presença de sanitaristas nos serviços de saúde; a falta de definição de carreira profissional; os baixos salários; a disponibilidade de recursos docentes. A pequena aceitação das disciplinas de Saúde Coletiva pelos alunos de Medicina, ao menos em algumas escolas médicas, talvez contribua para a redução no preenchimento de vagas.

A necessidade quase imperiosa de racionalizar o atendimento à saúde no país deveria, ao menos potencialmente, acarretar um aumento na demanda por profissionais com formação em Epidemiologia. Um possível caminho neste sentido seria a criação e consolidação de Núcleos de Epidemiologia nos grandes hospitais, muitos deles vinculados a faculdades de Medicina. Como este movimento é ainda incipiente, torna-se difícil avaliar suas repercussões. Contudo é lícito supor que haverá uma maior aproximação dos Departamentos de Medicina Preventiva com outros Departamentos das escolas médicas. Esses núcleos poderão se tornar ainda locais privilegiados para o treinamento em serviço da Residência.

$O$ candidato que ingressa atualmente na Residência em Medicina Preventiva/Saúde Coletiva apresenta um conhecimento de Epidemiologia extremamente limitado (quase nulo no caso dos aprimorandos não-médicos). Isto torna necessário retomar noções praticamente básicas de Epidemiologia no primeiro ano do Programa. Considerando o pequeno conhecimento inicial e a carga horária disponível para Epidemiologia no primeiro ano, pergunta-se se é possível a formação de recursos humanos em Epidemiologia no período de um ano. A questão poderia ser ainda desdobrada: mesmo para os residentes de Medicina Preventiva que não pretendem se "especializar" em Epidemiologia, o conteúdo oferecido no primeiro ano é suficiente?

O parágrafo anterior remete para a especialização em Epidemiologia durante o Programa de Residência em Saúde Coletiva. Este movimento, de surgimento relativamente recente, deve ser estimulado? Ele não poderá causar um distanciamento com outras disciplinas da Saúde Coletiva? Por outro lado, o crescimento da Saúde Coletiva, e especificamente da Epidemiologia, não tornariam esta especialização praticamente inevitável? Não seria este o momento 
de se repensar o conteúdo e currículo dos Programas de Residência em Medicina Preventiva?

Uma questão a ser levantada é a participação em Programas de Residência de outros Departamentos, por exemplo para demonstrar aplicações do método epidemiológico nas disciplinas clínicas. Outra questão semelhante seria a possibilidade de oferecer residência especializada em Epidemiologia (por exemplo no 30 ano) para indivíduos que fizeram residência em áreas clínicas. Essas questões colocam o problema da aproximação da Epidemiologia com a Clínica e o seu possível afastamento das outras disciplinas que compõem a Saúde Coletiva.

Os Programas de Mestrado e Doutorado apresentaram significativo crescimento nos últimos dez anos. Atualmente existem no Estado de São Paulo quatro programas de Mestrado e Doutorado em Saúde Coletiva e um de Mestrado (este exclusivamente em Epidemiologia). Algumas das limitações da Universidade, tornam-se aqui mais evidentes. Por exemplo, muito embora não se possa dissociar a pesquisa da docência em nível de Graduação e Residência, as limitações de recursos nas Universidades, em especial para pesquisa, tem maiores repercussões na Pós-Graduação senso estrito. A não expansão, e mesmo a redução do número de docentes em algumas universidades, tem trazido sérios prejuízos para a formação de recursos humanos em nível de Mestrado e Doutorado. Em sentido contrário, o número expressivo de indivíduos com pós-graduação no exterior tem reforçado o quadro docente de alguns Programas.

Um movimento que vem se expandindo nos Programas de Pós-Graduação em geral é o encurtamento da sua duração. Pensado especialmente para o Mestrado, isto representaria uma alteração do seu caráter. Entre as possibilidades aventadas incluem-se a contabilização de atividades da Residência como créditos e uma revisão crítica de literatura ser considerada suficiente como dissertação. Ao mesmo tempo, pretende-se que não ocorra queda da qualidade.

A maioria dos docentes e egressos dos Programas de Pós-Graduação está de acordo que a duração dos Mestrados era excessiva. A maioria também admite a necessidade de mudar a natureza da dissertação. No entanto, para reduzir a duração de modo apreciável, sem perda acentuada da qualidade, parece imprescindível concentrar a Pós-Graduação em disciplinas específicas. Ou seja, o aluno terá menor tempo de cursos e leituras em outras disciplinas da Saúde Coletiva. Isto implicará o risco do afastamento referido anteriormente.

Um outro problema, e antigo, tem sido pouco discutido: o tempo dedicado pelos alunos à Pós-Graduação, em nível de Mestrado e Doutorado. Além dos recursos docentes e materiais disponíveis quando da formação no exterior, uma das maiores vantagens (a maior?) é a dedicação praticamente integral ao Programa. Por que isto não ocorre no Brasil? Uma das razões apontadas é o valor da bolsa, consideravelmente maior no exterior. Agregaria outra: o grau 
de exigência institucional e a própria exigência que o candidato se impõe. Sugiro que os candidatos à Pós-Graduação, em particular para o Doutorado, refletissem seriamente antes da inscrição e se perguntassem: "quanto tempo disponho (ou pretendo) para dedicar ao Programa?” Para responder é necessário lembrar que a finalidade do Doutorado é formar pesquisador, e que sua duração foi reduzida.

Uma questão de grande relevância é o financiamento dos projetos dos alunos de Pós-Graduação. Dada a limitação de recursos, algumas sugestões têm sido levantadas: a participação do aluno em projetos em andamento e o aproveitamento de dados secundários. Realmente, o número diminuto de estudos ecológicos realizados no país aponta para a pequena utilização de dados já colhidos. Pode-se sugerir ainda a realização de estudos de validação, em geral não complexos, mas de extrema necessidade. A consolidação dos Núcleos de Epidemiologia em hospitais universitários pode também abrir novas possibilidades de investigação.

Em conclusão, o estado atual de desenvolvimento da Epidemiologia no Brasil permite visualizar alguns caminhos possíveis. As opções, a serem tomadas em prazo relativamente curto, terão importantes repercussões na área e provavelmente (espera-se) na situação sanitária.

\section{Bibliografia}

ABRASCO, Comissão de Epidemiologia. Rumos da Epidemiologia Brasileira: Reunião Nacional de Avaliação e Perspectivas (1984-1994). [Mimeografado, 1994] 